Literature Reviews

\title{
On Destructive Peri-implant Bone Loss
}

\author{
Andre J. Viljoen \\ 7 Bayside Street, Broulee, NSW, 2537, Australia
}

Article history

Received: 10-09-2019

Revised: 12-11-2019

Accepted: 19-11-2019

Email: andrejv@bigpond.com

\begin{abstract}
Destructive peri-implant bone loss is distressing for both the patient and the treating dentist(s). In severe cases peri-implant bone loss may cause jawbone mutilation, making re-treatment highly complex or impossible and violating the treatment philosophy of "first, do no harm". There are a multitude of causes of bone loss around a dental implant. These include, but are not limited to, post-operative bone remodeling; the skills or otherwise of the surgeon, the restorative dentist and technicians; patient factors (smoking, bruxing, health and disease of the oral hard and soft tissues, systemic disease); a disbalanced immunobiological response to the placement of a foreign body; the physical, chemical and topographical properties of the implant; and the response of the commensal bone biofilm populations to the placement of the implant. This paper looks at one possible cause of destructive, peri-implant bone loss and the response of the commensal bone biofilms to the placement of the implant, including the influence that surface topography may have on the behavior of the biofilm populations. A new classification of bone quality and health, based on radiographical anatomy and the associated microbial ecology, is proposed. An aetiology of biofilm-mediated, surface-induced, destructive peri-implant bone loss is described.
\end{abstract}

Keywords: Dental Implants, Implant Surfaces, Bone Quality, Biofilm, Destructive Peri-Implant Bone Loss

\section{Introduction}

Dental implants in use prior to the introduction of Brånemark's osseointegration concept comprised a variety of intra- and extra-bony devices such as the subperiosteal implant, the blade implant, the transosteal bone staple, the ramus frame and bone pins. All were susceptible to infection which often caused significant bone destruction and jawbone mutilation. These implant types never gained acceptance in the wider dental community because of their potential for harm and the experimental nature of these devices.

\section{Per-Ingvar Brånemark - the Father of Modern-Day Implant Dentistry.}

The seminal publication by Brånemark and coworkers entitled "A 15-year study on osseointegrated implants in the treatment of the edentulous jaw" (Adell et al., 1981) saw the dawn of a new era in dental rehabilitation using implantable devices. Brånemark showed that osseointegrated implants could indeed provide safe, predictable, long-term function using multiple root-form implants to support dental prostheses. The use of multiple implants rather than a single-unit device, such as a subperiosteal implant, reduced the chance of failure of the complex as a whole and importantly, it was found that should an implant fail, it caused little or no additional hard tissue loss, similar to that caused by the loss of a loose tooth (Brånemark et al., 1985).

Acceptance of the osseointegration concept by the dental profession was initially quite slow due to the professions' concerns about the safety of root-form implants and the potential harm that they could cause. Indeed, Jemt and Olsson (2014) note that "research had to focus on implant failures and associated complications to try to convince a sceptical dental community that osseointegrated dental implants functioned in clinical practice".

Would a "Sceptical Dental Community" Have Embraced Osseointegration if Outcomes as Seen in Fig. 1c Had Been Reported?

The bioethic of "first do no harm" (primum non nocere) is a fundamental cornerstone of healthcare. 
Brånemark understood this and stated that "reconstructive procedures to be used in defect situations that are not life-threatening must be designed so that if the procedure fails, the patient is not in a worse situation than before the treatment..." and, further, that the patient should be left with "basically the same retention anatomy as before installation of the fixtures" (Brånemark et al., 1985). Brånemark found that when machined surface implants failed, a thin fibrous capsule formed between the implant and the bone, the implant was easily removed and there was minimal additional bone loss (Fig. 1a).

Although high levels of long-term success were achieved, especially in the mandible, Machined Surface Implants (MSIs) were not $100 \%$ successful, especially in poorly trabeculated (Q4) bone, often found in the maxilla and posterior mandible, where primary stability could be difficult to achieve. In the search for ever greater success, Wennerberg (1999), amongst others, showed that Moderately Roughened Surface Implants (MRSIs) integrated faster and with greater Bone-Implant-Contact (BIC) than MSIs. Early research showed that a greater torque force was required to remove these implants than that required to remove smooth surface implants (Henry et al., 2000). They found that a moderately roughened surface induced a genetic upregulation of the progenitor stem cells in bone and periosteum, causing faster stem cell aggregation onto the implant surface and reducing early failure rates compared to those of turned surfaces. Importantly, the bone bed was believed to be sterile. The possibility of the presence of cells other than mammalian, including bacteria, was simply not entertained, despite the fact that Sanders and Sanders (1984) noted that of the one hundred trillion cells that make up the human body, only $10 \%$ are mammalian and that "the remainder are the microorganisms that comprise the resident microflora of the host".

Modified surfaces have been shown to have higher levels of initial success than machined surfaces (Smeets et al., 2016) and this success has led to an international shift away from the use of the traditional, tried-and-tested minimally rough MSIs $\left(S_{\mathrm{a}}\right.$ 0.5 to $1.0 \mu \mathrm{m})$, which Brånemark and co-workers favoured, to various forms of moderately rough implant surfaces, ranging in $S_{a}$ from 1 to $2 \mu \mathrm{m}$.

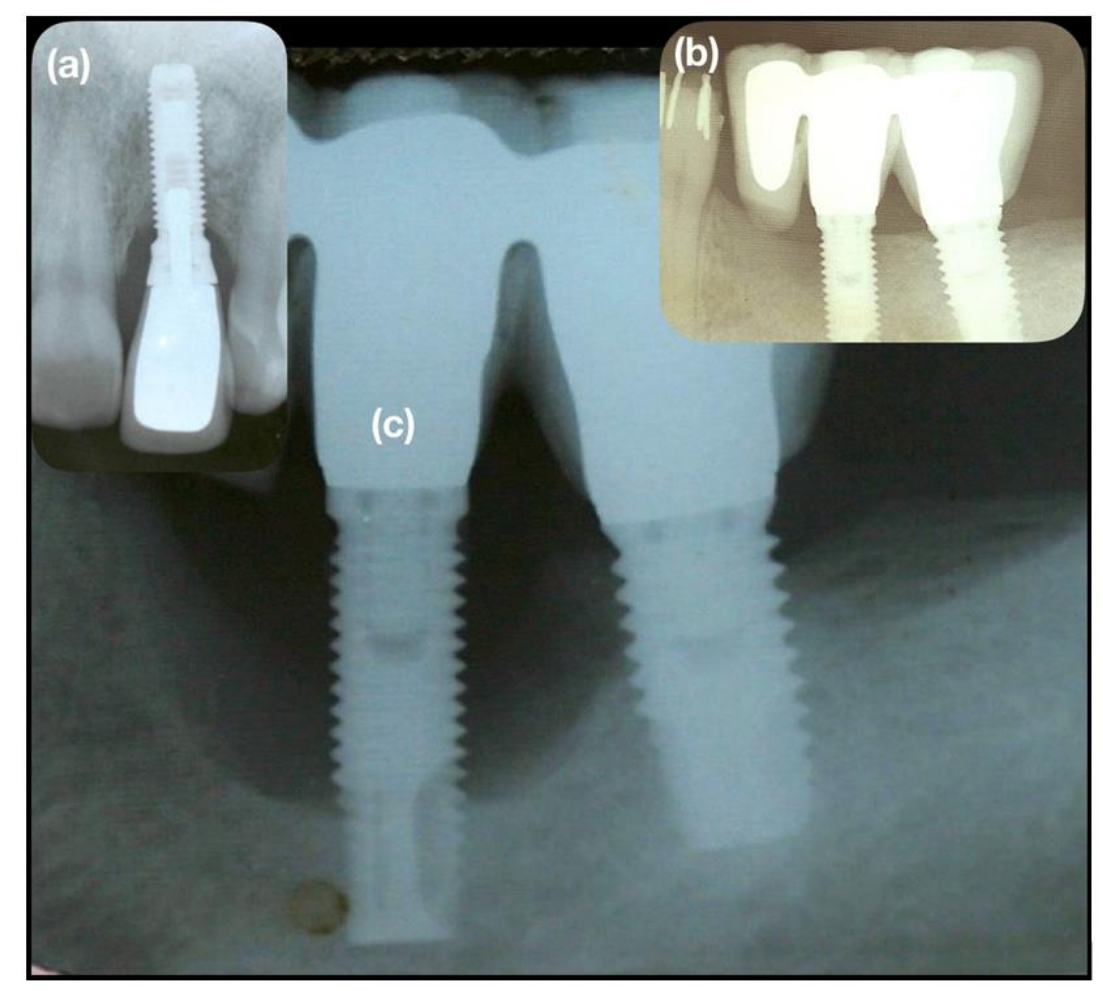

Fig. 1: (a) a failed machined surface implant after ten years of function. Note the benign mode of failure even though the implant had been mobile for several months. The patient only presented because of crown super-eruption; (b) radiograph of an anodised implant reconstruction two years after placement of the prosthesis showing stable marginal bone; (c) the same case as (b) 5 years after placement - note unacceptable cratering or cupping bone loss about the mesial implant. 
Many techniques have been utilised to alter surface topography. Surfaces may be roughened by adding to the surface, subtracting from the surface or modifying the surface, e.g., LASER modification (Wennerberg and Albrektsson, 2009; Smeets et al., 2016). Each different technique used for surface modification may produce vastly different surface topographies (but still have similar $S_{a}$ values), as (Ballo et al., 2011) graphically showed; for example, anodising increases surface roughness but it also creates micropores of 3-15 micron diameter that other techniques do not.

In summary, modern-day dental implants have a surface roughness between 1 and 2 micron and anodised surfaces include micro-pores. MRSIs integrate more quickly than MSIs with greater BIC. Both initial and medium-term results are better for MRSIs (Jemt et al., 2015).

\section{On Human Jawbone, Biofilm and Surfaces}

Although a moderately roughened surface appears to hold advantages over a smooth surface, there were a few early warning signs that mode of failure for MRSIs could be an issue. Åstrand et al. (2004) were one of the first groups to report on a different, more destructive mode of failure associated with modified titanium surfaces when they compared outcomes of titanium plasma-sprayed (TPS) implants against MSIs. They found that $9.1 \%$ of the TPS implants suffered unacceptable, highly destructive, periimplant bone loss, whilst none of the MSIs suffered destructive bone loss.

This raises a number of questions: why is there a difference in mode (not incidence) of failure? What if human jawbone supports permanent, resident bacterial biofilm communities? Could an altered surface topography also cause a genetic up- or downregulation of the bacterial communities, just as it does to progenitor stem cells? Could this explain the destructive pattern of bone loss sometimes seen about porous, anodised surfaces (Fig. 1c), as compared to the benign mode of failure round MSIs. Could an altered surface be a factor in the reported rise in periimplant bone loss (Jepsen et al., 2015).

This paper will look at these questions and cast a wide net both inside and outside the dental literature in an attempt to find answers.

Whilst it is true than different authors use different criteria to measure and define pathologic peri-implant bone loss, making comparisons between studies difficult, there has been an increase in refereed publications regarding this problem in the literature.
Derks and Tomasi (2015) found that $46 \%$ of moderately roughened implants were associated with peri-implant mucositis, of which $22 \%$ progressed to peri-implantitis with associated bone loss. Carcuac et al. (2017) found that up to $65 \%$ of MRSIs were affected and Browaeys et al. (2014) found that $49 \%$ were associated with unacceptable peri-implant bone loss after 3 years. These rates compared to a rate of observed peri-implantitis for MSIs of just $2.4 \%$ over 20 years (Åstrand et al., 2008) and 1.8\% over 12-32 years (Simion et al., 2018).

\section{Is There a Difference in the Amount of Peri-Implant} Bone Destruction when an Anodized Implant Ails or Fails as Compared to the Failure of a MSIs?

In order to answer the question, 28 machined surface and 48 anodized surface ailing or failed implants (Nobel Biocare, Kloten, Switzerland) were randomly selected from three private clinic settings, two in Australia and one in New Zealand. The qualifications of the surgeons who placed the implants are MDSc, FRACDS(OMFS) (Clinic 1), PhD (Clinic 2) and MDS, MPhil, FRACDS (Clinic 3) and their combined implant dentistry experience is greater than 80 years.

ImageJ, a public domain software program (National Institutes of Health, USA) was used as a surface area measurement tool. The length and width of the implant was known and was used to calibrate ImageJ. The surface area of the implant was then outlined to test the accuracy of the calibration. Once the calibration was shown to be accurate, the radiographic, two-Dimensional (2D) surface area of peri-implant bone loss associated with the ailing or failed implant was measured. Loss of peri-implant bone was then expressed as a percentage of the radiographic 2D surface area of the implant which allowed implants of differing sizes to be compared. Thus, a measurement of $0 \%$ relative additional bone loss describes the failure of an implant with no measurable additional bone loss (the ideal situation), $20 \%$ relative additional bone loss describes a bony defect one-fifth the size of the 2D area of the implant and a measurement of $130 \%$ relative additional bone loss describes a 2D defect 1.3 times the 2D size of the implant, which represents a major osseous defect, falling outside of the bioethic "primum non nocere".

As can be seen in Fig. 2 below, the results from all three clinics reflect the same trend: mostly, there is significantly greater percentage of relative additional bone loss associated with ailing/failing anodised implants as compared to machined surface implants. 


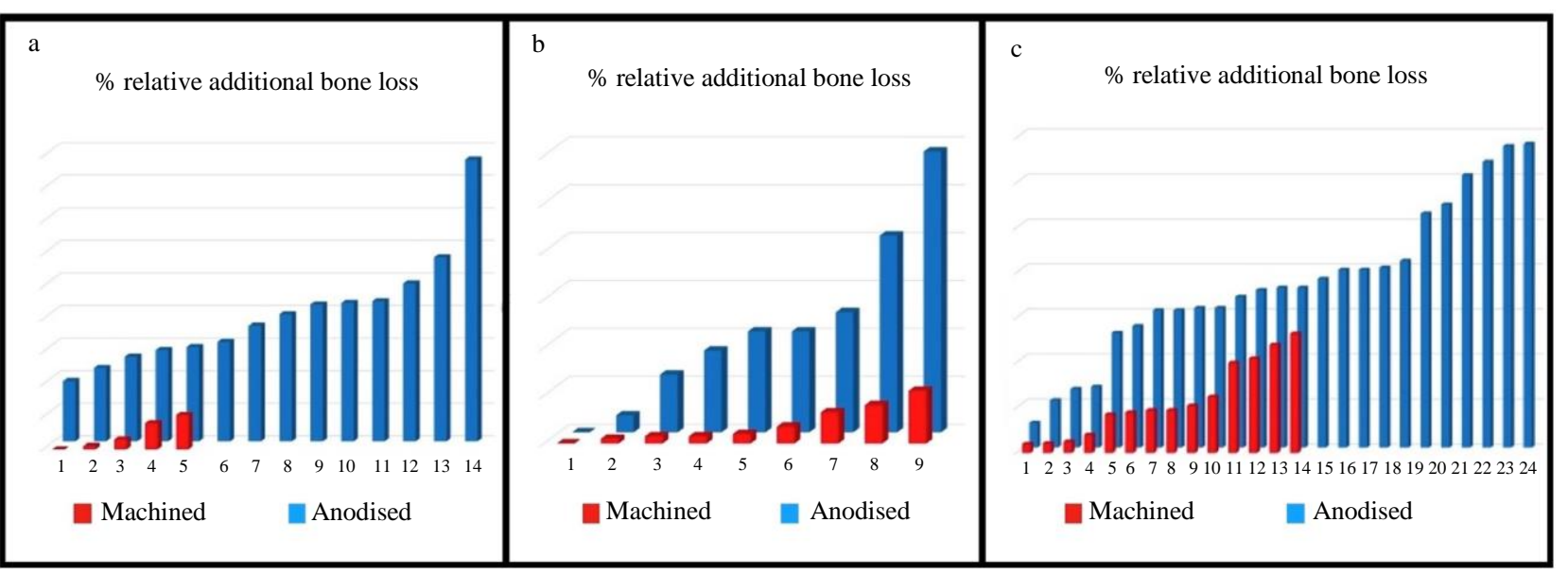

Fig. 2: (a) results for clinic 1; (b) results for clinic 2; (c) results for clinic 3. Note that all three clinics demonstrate the same trend: significantly greater peri-implant bone loss associated with the failure of anodised implants, compared to machined-surface implants. From unpublished data Aitken, Nelson, Viljoen 2017.

\section{On Human Jawbone}

There is general agreement in the orthopedic literature that "bones and joints are normally sterile areas" (Mader et al., 1999). The current model on which clinical implant dentistry is based also accepts that the human jawbone is a sterile compartment (there may be occasional planktonic bacteria in bone during bloodborne bacteraemias and tooth infections, but these planktons are quickly eliminated by the host's humoural and cellular immune systems). The Swedish team suggested that a well-vascularised bone-bed, free of residual infection, is essential for successful, long-term implant outcomes and regarded a three to six months post-extraction healing period as adequate for the resolution of tooth-associated bone infections, with a return to bone health and (presumed) sterility (Albrektsson et al., 1981).

The endodontic literature too describes a vigorous, unimpeded cellular and humoural immune response, which ensures that the presence of any extra-radicular planktonic bacteria is transitory and that dispersed planktonic bacteria are confined to the infected space of the root canal. Numerous authors suggest that the extraction of diseased teeth results in spontaneous bone healing and a return to bone sterility (Nair, 2006; Siqueira et al., 2014). However, when the periapical lesion persists and becomes chronic, a mixed osteolytic/osteosclerotic lesion develops and the presence of confining sclerosis delays or even prevents healing by convergence. Ingred Brynolf examined 320 cadaver specimens immediately post-mortem using histopathology and radiography and found that chronic apical tooth pathology is a mixed lesion, being both osteolytic and osteosclerotic (Brynolf, 1967). Eliasson et al. (1984) also found that sclerotic bone formed as a direct result of a chronic periapical infection. The sclerotic bone confined the periapical radiolucency. Whilst reactive sclerosis confines the lytic infection, it also isolates the residual pathologic biofilm nidus from the host immune defence mechanisms, from the capillary microvasculature, from antibiotic perfusion and from the surrounding margins of healthy, normalised tissue and healthy microbiota, thus allowing a nidus of chronic infection to persist. The orthopaedic literature supports the observations of the dental literature, noting that if bone infection has had a duration of one month or more, reactive sclerotic bone formation occurs (Waldvogel et al., 1970). Orthopaedic surgeons Zimmerli and Sendi (2017) agree, having found that the therapeutic value of antibiotics by themselves, without the additional assistance of surgery, ceases in the treatment of biofilm infection beyond one month. This finding is consistent with the observation that sclerosis creates "a host initiated bacterial line of defence" (Nelson et al., 2005).

Taken collectively, these findings indicate that if the nidus of infection is isolated from the host by sclerosis or if it is inadequately debrided (Patzakis and Zalavras, 2005), pathogenic biofilm communities may persist in the bone as latent infection, with an ever-ongoing potential for future pathology.

On what Basis was Human Jawbone Deemed to be Sterile?

Essentially, human jawbone has been deemed to be sterile based on flawed methodology. Traditional examination of human jawbone utilised culture 
microbiology, histological examination and Gram staining to detect the presence of bacteria. These techniques resulted in repeated negative results and thus supported the finding that bone is sterile. However, Tipton et al. (2017) noted that the above methods are not suited to the detection of biofilms. Tuttle et al. (2011) found that at best, the use of culture methodology may detect only $2 \%$ of the bacterial community populations. Thus, the use of methodologies best suited to the detection of planktonic bacteria rather than bacteria in biofilm, provided false negative results. Noted orthopaedic surgeon Dr Anthony Gristina describes wiping biofilm "slime" off an infected hip implant with his surgical glove, yet the culture results came back negative for the presence of bacteria (Gristina and Costerton, 1985). Costerton et al. (2003) captured this anomaly when they stated that "when a model used to analyse a [natural] process is incorrect, our attempts to understand and manipulate the process will fail [and] many honest and conscientious people will be frustrated [and hurt] and the reputations of whole research groups will be damaged".

Medicine has also used inappropriate methodology for the detection of microbes. For example, chronic otitis media with effusion was believed to be a sterile inflammatory lesion without any bacterial involvement. This misdiagnosis was perpetuated because "the majority of chronic effusions were culture negative, refractory to antibiotic treatment and positive for a variety of inflammatory mediators".
When this persistent, recurrent pathology was examined using biofilm-based methodologies such as Scanning Electron Microscopy (SEM) and Confocal Laser Scanning Microscopy (CLSM), bacterial biofilm communities were revealed in all mucosal specimens (Ehrlich et al., 2002).

Bjarnsholt (2013) noted that more than $80 \%$ of medical and dental bacterial infections are now known to be caused by organisms growing in biofilms.

\section{So, is the Human Jawbone Sterile?}

The seminal thesis by Nelson (2016) examined this question. Using 454 pyrosequencing suited to the detection of biofilms, Nelson found that the human jawbone is not sterile and that it supports permanent, commensal (resident) biofilm communities. He found that these communities may range from those that are non-pathogenic to the host tissue, polymicrobial, stable, diverse, even in genus, resistant and resilient to pathogen invasion; to communities low in diversity and high in pathogenicity. His results suggest that an almost infinite number of alternative stable (and non-stable) states exist (Shade et al., 2012).

Represented as a pie charts, two examples of biofilm communities found in human jawbone are presented in Fig. 3 below: (a) represents a non-pathogenic, stable bone-bed biofilm community and (b) represents a pathogenic community.

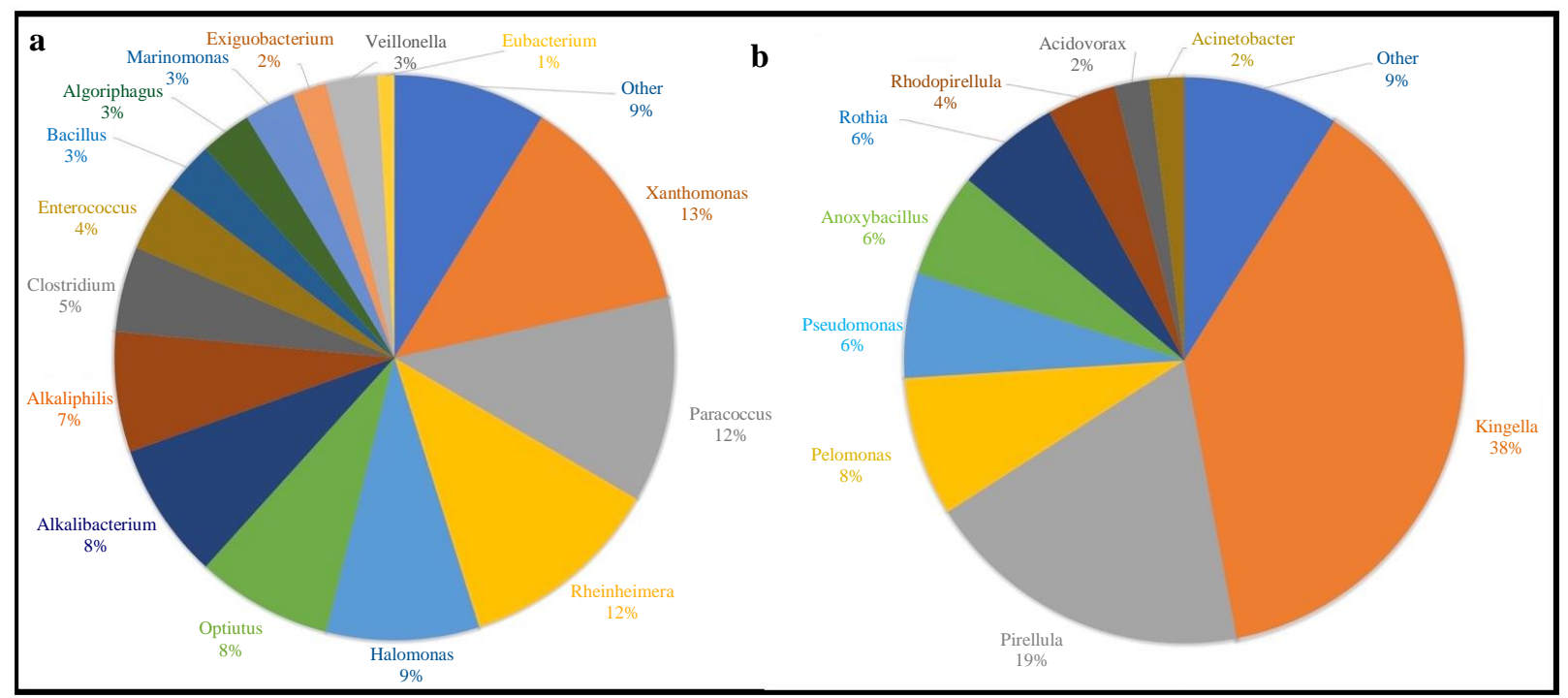

Fig. 3: (a) Pie chart that represents the resident genera in a pristine, non-pathogenic human jawbone community. Note that no one genus dominates (evenness of genera) and that there is a large mix of genera (rich in diversity). This diversity makes the community resistant to invasion and if invaded, it bounces back quickly (resilient). (b) Pie chart representing a pathological site. Note the unevenness of genera and the dominance of the pathogen Kingella. This sample was taken at the time of an implant insertion. Not surprisingly, the implant failed 12 days later. Courtesy of Dr Stephen Nelson 2016. 
Nelson took 222 samples from 68 patients during traditional two-stage implant treatment. Samples included the following clinical groups:

- Inherited (non-debrided) Apparently Healed Bone (IAHB)

- Debrided, Apparently Healed Bone (DAHB)

- Lytic (Q4) bone

- Sclerotic (Q1) bone

- Pristine or Congenitally Absent Bone (CAB)

- Granulation tissue

- Serous effusion from extraction sockets

- Failed implants

Additionally, plaque and saliva samples were collected from each patient and Terminal Restriction Fragment Length Polymorphism (TRFLP) analysis was used to monitor for contamination, in accordance with established biofilm detection guidelines. SEM was used to visually confirm the presence of bacterial biofilm. DNA was extracted from dental samples directly and the presence of bacterial populations was determined using 454 pyrosequencing (b-TEFAP). SEM also confirmed pathogenic bacterial biofilms persisting in diffuse osteosclerotic periapical bone and in long-term osteolytic and osteosclerotic bone.

Nelson found universal bacterial biofilm presence in all samples, independent of bone health, disease or healing time after disturbance. A 20-phylum human jawbone microbiome was identified.

Areas of congenital tooth absence (agenesis of both the deciduous and permanent teeth) provided sites of pristine bone; these sites had never been contaminated by tooth pathology and were used to act as a 'control' of the bone microbiome resident in healthy, normal, homeostatic bone. Having a reference population of the composition of a healthy microbial ecosystem allowed him to compare, using multivariate statistical ordination, other communities against this health-control and thereby determine the health-status of those communities.

Multivariate statistical ordination of the bacterial community members present in the biofilm samples revealed ecological separation between the different clinical groups described above. For example, regenerative surgically debrided groups (DAHB) revealed improved microbial ecological recovery and radiographic bone quality, compared to their predebridement microbiome and radiographic anatomy. Significantly, they ordinated closer to the healthcontrol than the non-debrided groups.

\section{What is Regenerative Surgical Debridement?}

Regenerative Surgical Debridement (RSD) is a procedure whereby diseased bone (bone supporting pathogenic biofilm communities and with altered anatomy) is surgically reunited with bone supporting healthy biofilm communities (Simpson et al., 2001). RSD mostly causes a commensal population shift in the diseased bone back to a diverse, stable, resistant and resilient (healthy) community. Additionally, a radiographic return to normal bone anatomy was noted if the debridement was successful in effecting a population shift. Nelson found that although RSD resulted in the resident microbial communities ordinating closer to the health-control, with the return of normal radiographic bone anatomy, RSD did not return bone to sterility, i.e., all bone samples still hosted biofilm communities.

\section{Have Jawbone Quality and Health Been Previously Defined?}

As Lindh et al. (2014) observed, "bone quality is considered to be an important parameter for implant treatment outcome, but there is no consensus on what bone quality means or on how to assess bone quality".

When Lekholm and Zarb introduced their proposed bone quality index (Brånemark et al., 1985), they commented that there was "great variety in jawbone anatomy" and they proposed that bone with altered cortical and trabecular anatomy were simply variants of normal healthy bone. Their index failed to define a health-control of normalised, homeostatic bone. Rather, it provided "a reference range" of apparently normal variants of bone quality. Surprisingly, the Lekholm and Zarb index remains the most commonly used bone quality assessment tool in implant dentistry (Lindh et al., 2014).

\section{What are the Bone Bed Requirements for Successful Osseointegration?}

From the outset, healthy bone tissue was seen as an essential prerequisite for the osseointegration of oral implants (Albrektsson et al., 1981). A non-infected bone bed was deemed to be imperative for proper osseointegration. Brånemark's research on microvasculature had established that bone regeneration required a wound that was connected to the periosteum and the capillary microvasculature as well as the eradication of endotoxin-secreting gramnegative microbial pathogens (Brånemark and Breine, 1964; Brånemark, 1965; Brånemark and Urbaschek, 1967). Residual infection was seen as a contraindication to implant installation (Adell et al., 1981). Despite understanding the importance of bone 
health, the Swedish team did not test the theory that tooth removal in itself delivered a sterile recovery from pre-existing infection.

Nelson and Thomas (2010) tested this hypothesis using enhanced bacterial culture and found bacterial persistence in apparently healed, edentulous bone in $21 \%$ of cases. Around the same time, Kassolis et al. (2010) found, using histopathology, that $51 \%$ of bone (after a minimum 12 months healing) was either nonviable or osteomyelitic, confirming the long-term presence of bacteria in bone.

Lekholm and Zarb considered apparently healed bone with osteolytic or osteosclerotic architecture as just a normal variation of spontaneous sterile healing (Brånemark et al., 1985). However, as early as 1962, Parfitt showed that the absence of trabeculation in both lytic and sclerotic bone was a biological marker of residual pathology (Parfitt 1962). Therefore, Lekholm and Zarb's suggested variations of healthy bone with altered trabecular architecture may actually represent bone with impaired healing, supporting pathogenic biofilms, sufficient to contraindicate implant placement.

\section{A New Classification of Bone Quality.}

Based on Nelson's research, bone quality as determined radiographically (Fig. 4) can now be directly related to the microbial populations that they support, which allows an ecologically-based classification of bone quality to be described.

Nelson's samples included both osteosclerotic (Q1) and osteolytic (Q4) bone. He also sampled Q2 and Q3 bone. Pyrosequencing and ordination of the supported commensal biofilm communities enabled the development of a new classification of bone quality, health and disease. Both sclerotic bone (Q1/D1) and lytic bone (Q4/D4) are diseased bone and were shown to support a pathogenic microbiome. An additional bone type was identified, which is described as a mixed bone type (D5) often seen postextraction, with areas of lysis confined by sclerosis and trabecular disruption. Only $\mathrm{H} 2$ and $\mathrm{H} 3$ are healthy bone, with normal radiographic anatomy, which Nelson has shown supports a non-pathogenic, stable, diverse and homeostatic microbiome, ordinating closer to that of the health-control.

\section{What does D5 Bone Look Like Radiographically?}

Just as the recognition of radiographic anatomical structures takes time and practise to learn, so too does the radiographic recognition and classification of bone quality and the detection of residual niduses of infection bounded by sclerosis. Nonetheless, it does not take long to acquire the skill. An example of D5 bone is shown in Fig. 5. Figure 6 shows the outcome of placing anodised implants into D5 bone.

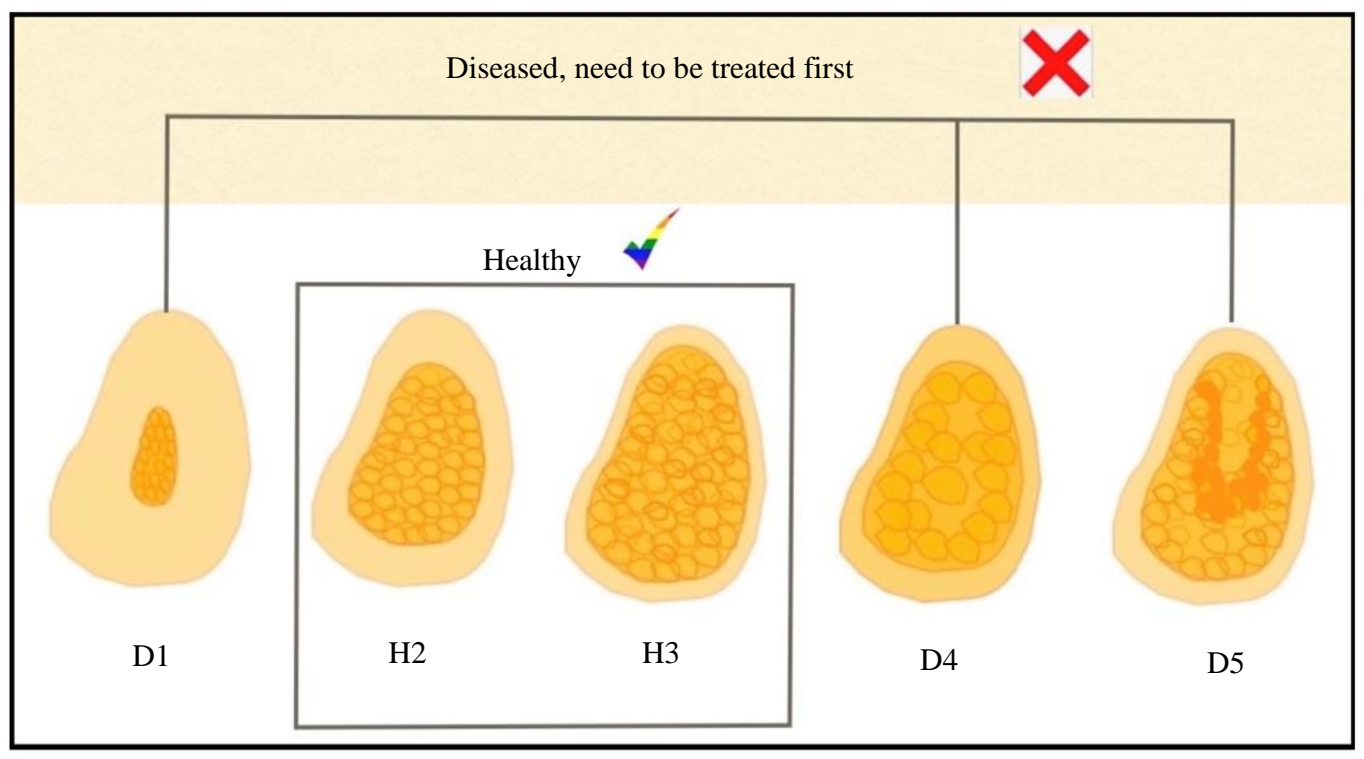

Fig. 4: A new classification of bone health and disease. D1 = diseased sclerotic bone with a compromised capillary blood supply, increased cortical thickening and trabecular densification, supporting a pathologic microbiome that ordinates away from that of the health-control; $\mathrm{H} 2=$ normal healthy bone exhibiting robust cortical and trabecular bone supporting a stable and diverse microbiome (mostly anterior mandible); $\mathrm{H} 3$ = thinner cortex but similar trabecular bone to $\mathrm{H} 2$, with a stable and diverse microbiome (mostly anterior maxilla); D4 = diseased bone exhibiting trabecular disruption and lytic areas, supporting a pathologic microbiome; D5 = diseased bone exhibiting areas of dense or diffuse sclerosis surrounding lytic areas (often postextraction) with trabecular disruption, in which the microbiome ordinates away from the health-control 


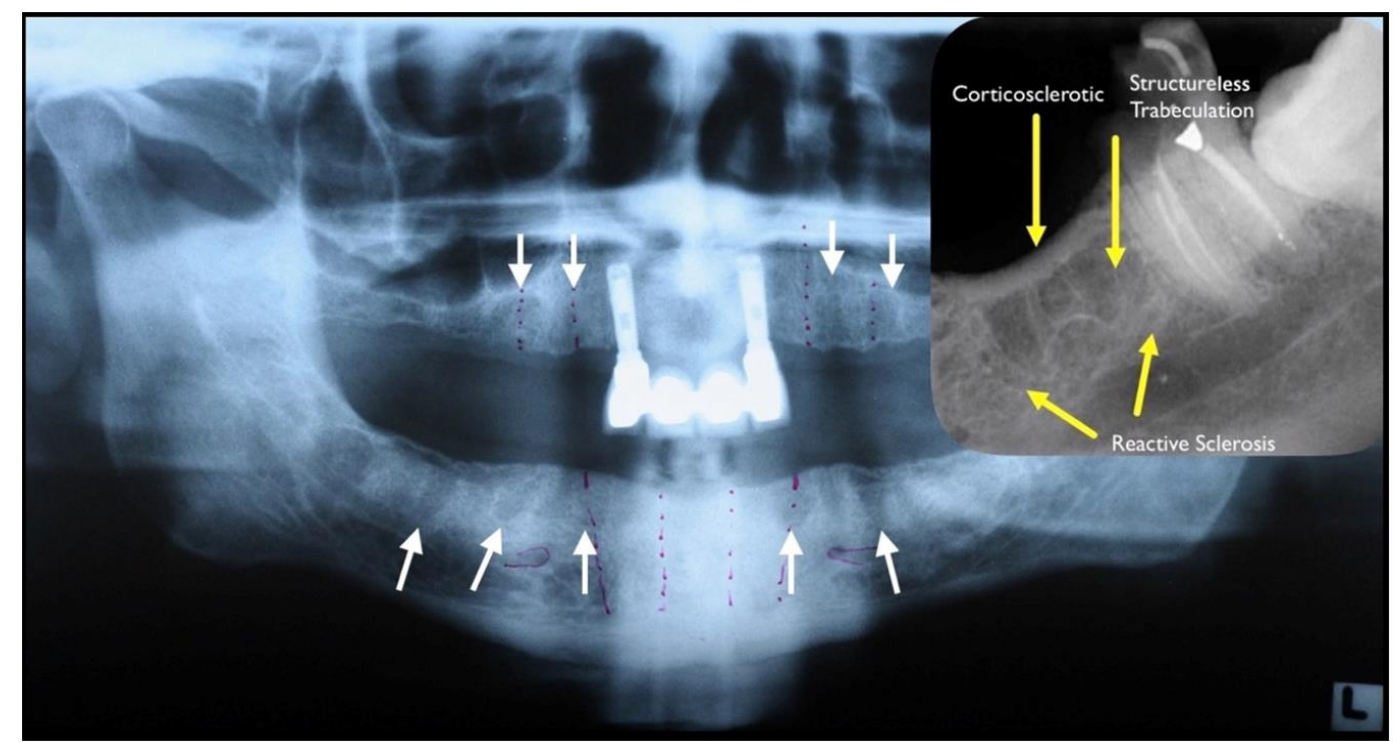

Fig. 5: D5 bone. The orthopantomogram (OPG) was taken 3 years after tooth removal. No debridement was carried out at the time of tooth removal. Note multiple areas of lytic bone surrounded by confining sclerosis. The two maxillary implants are MSIs. The superimposed periapical view shows more specific detail, with diffuse sclerosis surrounding areas of disconnected pockets of bone with trabecular disruption

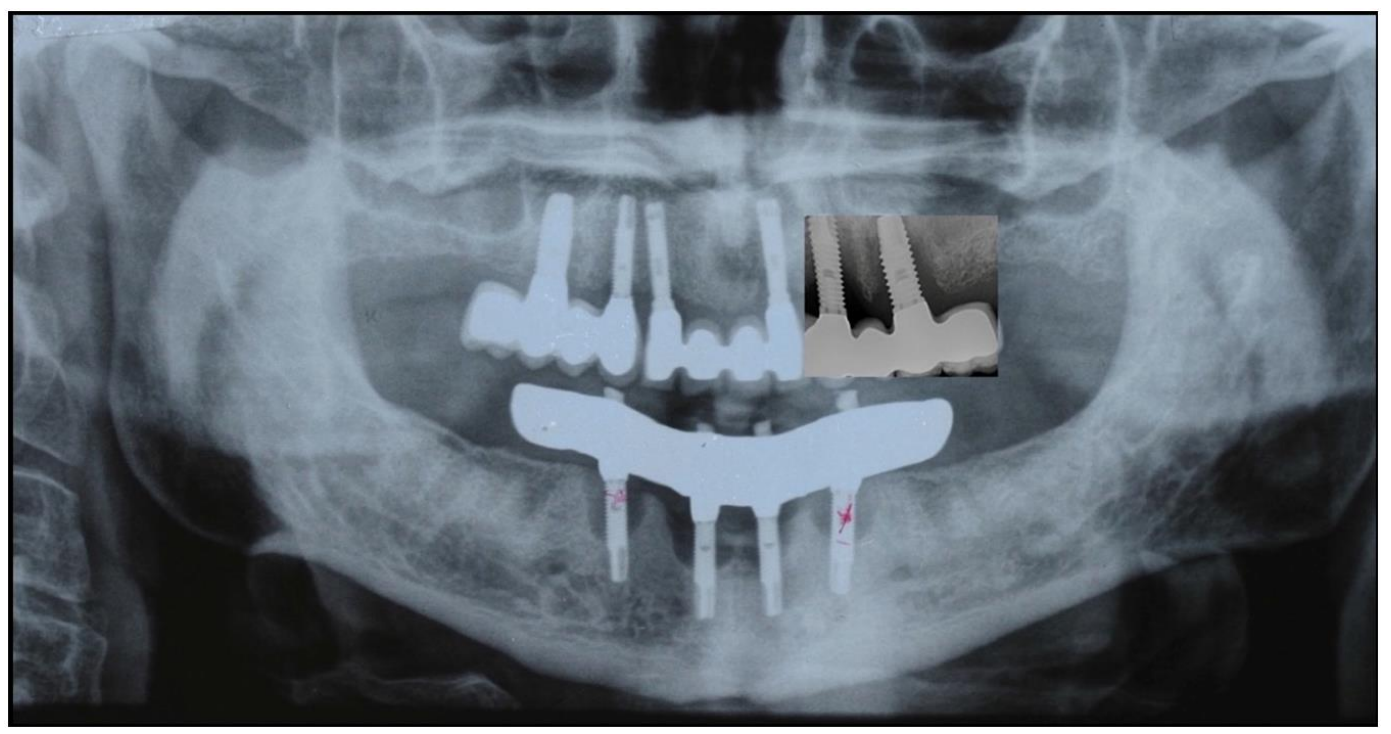

Fig. 6: The same patient as in Figure 5. The placement of anodised implants into undebrided D5 bone in the mandible resulted in the destructive loss of all 4 implants after 8 years. The left-hand maxillary posterior implants failed destructively after 5 years (superimposed periapical image). Remedial treatment will be complicated because of the size of the defects. The anterior 2 maxillary machined surface implants remain unaffected after 25 years of continuous function

\section{Only $\mathrm{H} 2$ and H3 Bone Beds are Suitable for Implant Placement.}

A classification of bone quality and ecological microbial health or disease has been described based not only on radiographic observations but also on the resident microbiome shown to be associated with that bone quality. Accepting that implants should be placed into healthy tissue, then only $\mathrm{H} 2$ and $\mathrm{H} 3$ are suitable bone beds and D1, D4 and D5 need to be either returned to microbial ecological health using RSD prior to implant placement or avoided. Notably, not all bone beds respond to a single surgical debridement and the debridement procedure itself may be surgically and technically demanding (Lidgren and Törholm, 1980). That tooth extraction does not result in a spontaneous 
return to a non-pathogenic microbiome community invalidates the placement of implants immediately postextraction if there is apical tooth pathology. Furthermore, because $\mathrm{H} 2$ and $\mathrm{H} 3$ are both bone beds of robust health and quality, the use of moderately roughened surfaces to stimulate progenitor stem cells and facilitate osseointegration is not required. Smooth, non-"alien" (Ehrlich et al., 2008), biofilm-resistant, minimally rough MSIs can be used with high levels of primary stability and predictable, long-term success, as shown by Simion et al. (2018).

In summary, human jawbone is not sterile and D1, D4 and D5 bone qualities are diseased bone states, unfit for implant placement.

\section{On Bacteria and Biofilm}

Accepting that the human jawbone is not sterile and supports permanent biofilm communities, then further understanding of these microbial communities is required.

\section{In what Form do Bacteria Live in the Earth's Environments?}

Of the Earth's entire microbial biomass, 99.9\% of bacteria live in biofilm communities. Only $0.1 \%$ occur as free-floaters, otherwise known as planktonic bacteria (Costerton et al., 1995).

\section{What are Biofilms?}

Biofilms are mostly polymicrobial aggregations or communities of microbes encased in a protective extracellular matrix (slime) that are adherent to a surface. Biofilms are sessile and do not form without the presence of a substrate. Microbiologists have long known that smooth surfaces $\left(S_{\mathrm{a}} 0.5 \mu \mathrm{m}\right.$ or less) resist planktonic attachment - the first stage in biofilm formation - and subsequent biofilm formation whilst moderately roughened surfaces $\left(S_{\mathrm{a}} 1\right.$ to $\left.2 \mu \mathrm{m}\right)$ promote planktonic attachment and biofilm formation (Costerton et al., 1978).

\section{How do Biofilms Form and Grow?}

Biofilms form when planktonic bacteria find a suitable surface and adhere to it. These early colonisers explore the surface and environment and, if suitable, irreversibly adhere to it. If unsuitable, the initial attachment is reversible. Within as little as 12 minutes, the production of an extracellular matrix can occur and a young biofilm colony is formed. A secreted matrix is a distinguishing hallmark of all biofilms. The matrix comprises polysaccharides, alginates, extracellular DNA, proteins and lipids. It is an outstanding defensive structure and protects the bacteria from UV light, antibiotics, desiccation and the host's humoural and cellular immune systems. Antibiotic resistance also occurs due to the much lower metabolic rates of bacteria resident in biofilms than that of their planktonic counterparts. Biofilms have well-developed efflux pumps that remove waste and bactericidal agents. Additionally, a small percentage of the colony exists as persister cells, which are metabolically dormant and do not initially undergo cell replication. Lewis (2005) stated that "persisters are essentially altruistic cells that forfeit propagation in order to ensure survival of kin cells in the presence of lethal factors". They avoid immunological detection and are not harmed by antibiotics, but these cells may "awaken" once conditions improve and this strategy may give rise to inflammation and chronicity of infection (Wannfors and Hammarström, 1989; Costerton et al., 2003). The biofilm gradually matures with the formation of nutrient channels and mushrooming. Genetic changes occur and the members of the community behave quite differently than their planktonic cousins. Cell specialisation occurs and a cell-cell signal system develops called Quorum Sensing (QS). Importantly for the survival of polymicrobial biofilm communities, QS occurs between bacteria of different species. QS is the "lingua franca" of biofilms. It also controls biofilm formation, species interaction, growth, endotoxin production and virulence. The final phase in the lifecycle of a biofilm is planktonic dispersal, with the formation of new colonies (Deva et al., 2013).

\section{On Implanted Surfaces}

Microbiologists have long understood the relationship between the implanted surface and biofilm formation with associated infection. Just as the surface topography can upregulate progenitor stem cells and stimulate bone growth and osseointegration, surface topography has also been shown to be able to up- or down-regulate microbial genetic expression, which may play a role in the selection of which bacteria stick to the surface. This selectivity on bacterial adhesion can in turn deliver a biofilm of specific pathogenicity both on the implant surface and in the neighbouring bone (Zimmerli, 2014). In short, surface topography can determine the pathogenicity of the attached biofilm. Mukherjee and Bassler (2019) showed that micropores and crevasses (grooves) play a vital role in providing an ideal environment for biofilm microbes to transition to a "quorum-sensing-on mode", allowing the production of endotoxins, which destroys the periimplant capillary bone bed (Fig. 7), leading to ischemia, necrosis and destruction of the bone-bed. The phenotypic expression of a surface-adherent persistercell biofilm is characterised by chronic, recalcitrant, relapse infection (Lewis, 2010; Fisher et al., 2017). 


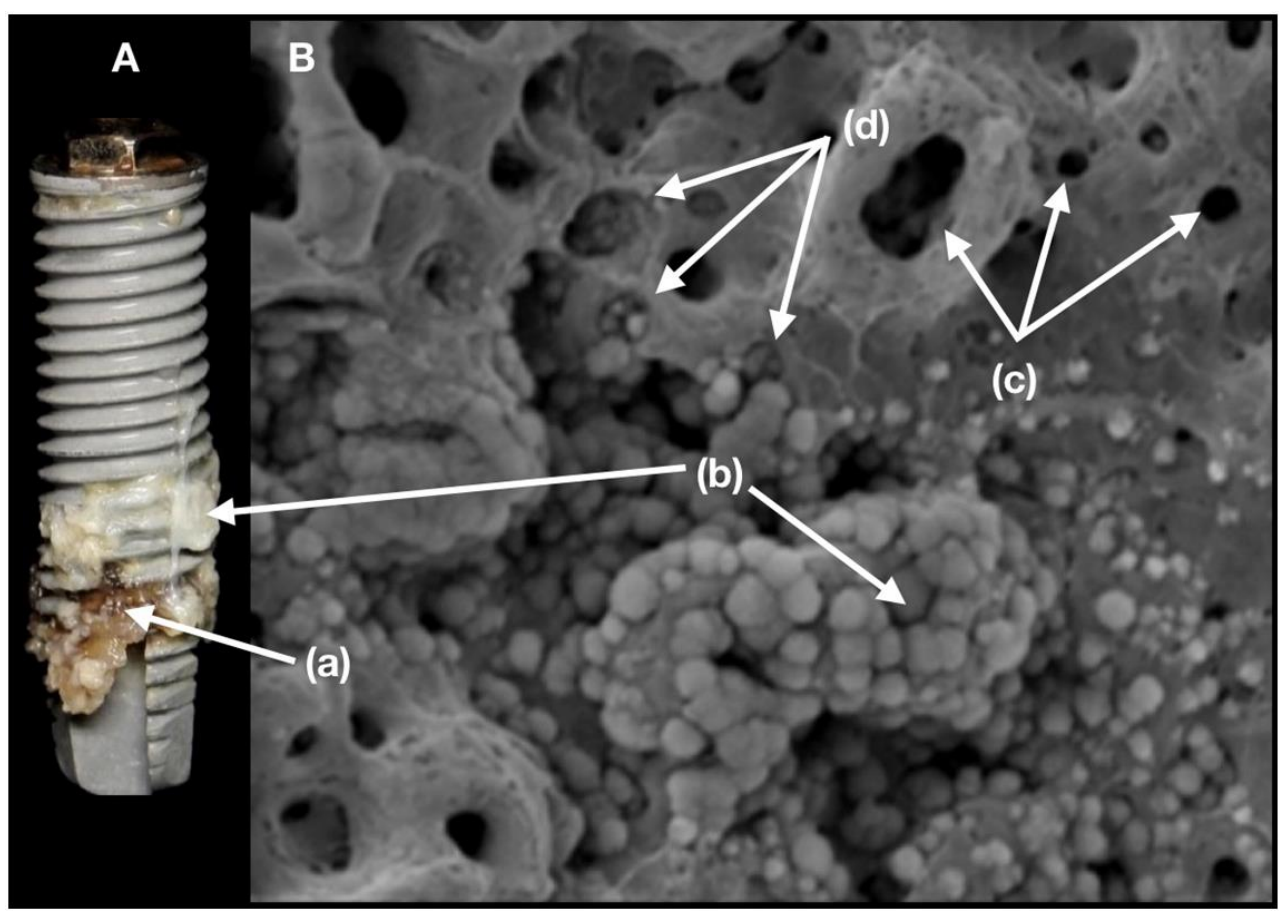

Fig.7: (A) Anodised implant at the time of removal with attached necrotic bone and biofilm slime (B) SEM of the same implant (a) necrotic bone (b) coccoid bacterial biofilm (c) micropores (d) endotoxin producing biofilm within the micropores. Courtesy Dr Rob Aitken

\section{What Type of Surface is Most Resistant to Microbial Attachment?}

Biofilms do not form without a surface and the surface topography of the substrate is an all-important factor in biofilm formation, because the smoother the surface, the harder it is for microbes to gain foothold and hence, for a biofilm to form (Arnold and Bailey, 2000). Additionally, if not a smooth surface, the characteristics of the surface topography will favour the adhesion of certain microbes over others, both nonpathogenic and pathogenic. Sweet et al. (2011) demonstrated that the physiochemical properties of the surface of marine coral favours the attachment of some marine microbiota over others. Appropriate topographic surface selection is critical for implanted medical devices to be able to resist pathogens (Berne et al., 2018). Costerton et al. (1978) observed that "if adhesion has a central role in the success of pathogenic bacteria, then prevention of adhesion should be an effective way to prevent infection". Thirty years later, Ehrlich et al. (2008) noted that the placement of an "alien" (roughened) surface can cause pathology by causing the loss of some of the biofilm community members. This makes the remaining community less diverse and therefore more susceptible to invading pathogens. Thus, the placement of a MRSI into a healthy bone microbiome (ie., $\mathrm{H} 2$ or $\mathrm{H} 3$ bone) is not without risk because the modified surface may alter the native, homeostatic community to a less resistant one, allowing pathogenic invasion. This risk is there for "the life-time of the implant" (Zimmerli et al., 2004). Percival et al. (2015) took the importance of the surface further when they stated that "an ideal in-dwelling medical device should possess surfaces that are similar to those of a healthy human cell, limiting bacterial adhesion and thus preventing infection. To achieve biocompatibility, the surface of the medical device should be smooth and uniform to allow the growth of healthy tissue and evasion of invading pathogens".

Clearly, two factors are essential for long-term implant success: an implant with a smooth, cell-like (non-alien) surface and a healthy bone bed supporting a stable, homeostatic bacterial microbiome. As Stephen Nelson (2016) observed, "the fact that bone regenerates around an oral implant may ultimately amount to nothing. The primary event for implant success is the restoration of the health ecology of the bone bed".

\section{Discussion}

This author first observed destructive, cupping or cratering bone loss around four anodised (moderately roughened) surface dental implants in 2010 (Fig. 6). This mode of failure was unlike anything previously seen about MSIs and the bone loss was so significant that the bioethic of "first, do no harm" was violated. Further cases presented and other clinics began observing and 
reporting the same destructive mode of failure. Thus began my quest for answers.

\section{Does Clinical Observation Play Any Role in the Study of Pathogenesis?}

Clinical observation plays a pivotal role in the study of pathogenesis. Costerton (2003) stated that "The gold standards in studies of human pathogenesis are clinical observations and patient data". He also pointed out that "biofilms are involved in the aetiology of both osteomyelitis and prosthesis-related infections" and that this phenomenon "is supported by the observations that these infections often develop months or years after surgical intervention and that the infections remain localized and often develop relatively slowly".

This statement closely reflects clinical observations seen around some moderately roughened surface dental implants. That is, initial high levels of success and marginal bone stability followed by unexplained, significant, peri-implant bone loss after approximately five to ten years of implant function. This observation may appear to conflict with published data, such as the conclusion of a recent large meta-analysis examining modified surface implant success and marginal bone height stability (Karl and Albrektsson, 2017). Their conclusion states that "implants with TiUnite (anodised) surface provide a predictable treatment modality". However, the authors also note that there is a "scarcity of data for the years 6 to 10" and "consequently, cautious interpretation of data beyond 5 years of follow-up is mandatory". This is exactly the time frame established by clinical observation that persister-cell-mediated periimplant destructive bone loss is observed and a metaanalysis with a paucity of data within this critical time frame may provide a misleading conclusion.

In summary, smooth surfaces do not favour planktonic bacterial attachment and persister-cell biofilm formation, whilst moderately rough surfaces do. Additionally, and importantly, surface topography may determine the pathogenicity of the attached biofilm. Pores in the surface have been shown to be linked with the production of endotoxins (Mukherjee and Bassler, 2019). An understanding of the relationship between bone quality, the microbiomes that bone supports and the role of surface topography allows us to generate a model of the aetiology of microbially-mediated, surfaceinduced, destructive, peri-implant bone loss.

\section{The Aetiology of Biofilm Mediated, Surface- Induced, Peri-Implant Bone Loss}

The preparation of an implant osteotomy using a series of twist drills into a bone bed that supports permanent, resident microbial biofilm communities fragments the biofilm and causes dispersal of planktonic bacteria, similar to that caused by sonication of failing prosthetic hip implants prior to aspiration for enhanced bacterial culture (Tunney et al., 1998; Trampuz et al., 2000).

Following the placement of the implant into the bone osteotomy, there is a "race for the implant surface" between progenitor stem cells and biofilm-dispersed planktonic bacteria, as described by Gristina et al. (19881989). Both stem cells and planktonic bacteria compete for attachment to the implanted surface. Importantly, the health/disease status of the dispersed planktonic bacteria reflects that of the parent biofilm and this in turn determines the health/disease status of the new biofilms that form on the surface of the implant.

A moderately roughened implant surface causes a genetic upregulation of the progenitor stem cells and aggregation on the implant surface. The competition between host cells and microbes for the surface creates a stressful ecosystem, causing a so-called environmental "SOS" signal (Lewis, 2010), which encourages the bacteria to go into a survival mode and form a dormancytype biofilm known as a persister-cell biofilm. This biofilm is almost metabolically inactive and initially nonreplicative; as such, it avoids detection and destruction by the host's immune system (Fisher et al., 2017).

Although an apparent oxymoron, persister-cell biofilm is not completely dormant and over a few to several years, from time to time it will disperse pathogenic planktonic bacteria, which impacts the homeostasis of the peri-implant bone bed. A gradual and progressive inflammation occurs in the neighbouring bone bed (Wannfors and Hammarström, 1989; Wannfors and Gazelius, 1991) which causes both physical and microbial community changes in the periimplant bone. The peri-implant bone bed gradually becomes what Marsh (2003) describes as a "microenvironment, which now favours different microbial communities and an opportunity exists for invading pathogens, with a potential for "ecological catastrophe".

In summary, the formation of persister-cell biofilm caused by the stress of competing with surface-induced, upregulated host primordial stem cells gradually changes the resistance and resilience of the commensal peri-implant microbial communities to those that are less able to resist invasion by other communities, including pathogens.

\section{The Stage is Set for Invasion}

For any number of reasons; systemic, local or both, a pulse or press-type disturbance (Shade et al., 2012) of the microbiome present in the peri-implant gingival sulcus may cause a population shift in the resident gingival community to a more pathogenic community and a peri-implant mucositis develops that is characterised by soft tissue inflammation without loss of supporting bone (Berglundh, 2019). This effect may in turn directly subject the crestal bone to an inflammatory infiltrate, delivering the initial phase of disturbance and 
causing a shift in the resident communities. Early postdisturbance colonisers may adapt rapidly to local conditions and may persist long-term, out-competing native community members and impeding community resilience (Shade et al., 2012). Ultimately, a population shift follows in the now-susceptible neighbouring bone microbiome to a more pathogenic community and/or initiates a full awakening of the persister-cell biofilm attached to the surface of the implant; this mechanism is known as a 'contiguous focus osteomyelitis'. Invasion of the peri-implant bone bed and metabolic activation of the persister-cell biofilm causes increased endotoxin production and a cascade of consequences. Endotoxin production may be further promoted by the presence of grooves and micropores in the implant surface, which facilitate quorum-sensing dependant production of endotoxins (Mukherjee and Bassler, 2019).

Further significant direct and indirect destruction of the single-cell bone bed endothelial capillary network occurs by compression lysis and/or endotoxin release (Wannfors and Gazelius, 1991). This development in turn causes avascularity, in which loss of the capillary microvasculature deprives the local tissue of the cellular immune system through loss of white cell diapedesis and loss of oxygenation and nutrients, causing bone necrosis and build-up of waste products. Ultimately, bone lysis and necrosis stimulate a reactive confining sclerosis. Clinically, this effect can be observed as destructive cupping bone loss surrounding the implant. The lesion becomes self-perpetuating and the bone destruction is significant, with implant- adherent biofilm causing a pathogenic population shift in the proximal bone microbiome until (if left untreated or undetected) a cavernous jawbone defect results, entirely surrounding the implant. This is graphically illustrated in Fig. 8, where such significant bone destruction has occurred that there is a risk of pathologic fracture of the mandible.

This mechanism is in contrast to the non-destructive mode of failure around smooth-surface implants. Osteotomy preparation causes exactly the same cloud of planktonic, biofilm-dispersed bacteria as previously described. Once again, there is a "race for the surface" between progenitor stem cells and planktonic bacteria, but the smooth surface of the implant does not illicit a genetic response, either in the stem cells or the planktonic bacterial cells. As Percival et al. (2015) note, a smoother implant surface, closer in surface characteristics to healthy human cells, plays an important role in "the evasion of invading pathogens". Some colonisers attach and if the bone bed is homeostatic, the resulting biofilm mimics that of the native bone biofilms. Importantly, pathologic persister-cell biofilms do not form on the surface of the smooth implant, avoiding chronic immune activation, chronic inflammation and chronic infection. As Jacombs et al. (2014) observed, the bacterial load after 24 h on smooth surface breast implants was 72 time less than that on roughened implants. There is a direct relationship between bacterial load and observed pathology and Jacombs noted that smooth-surface implants were associated with less pathology than rough-surface implants because of a lower bacterial load.

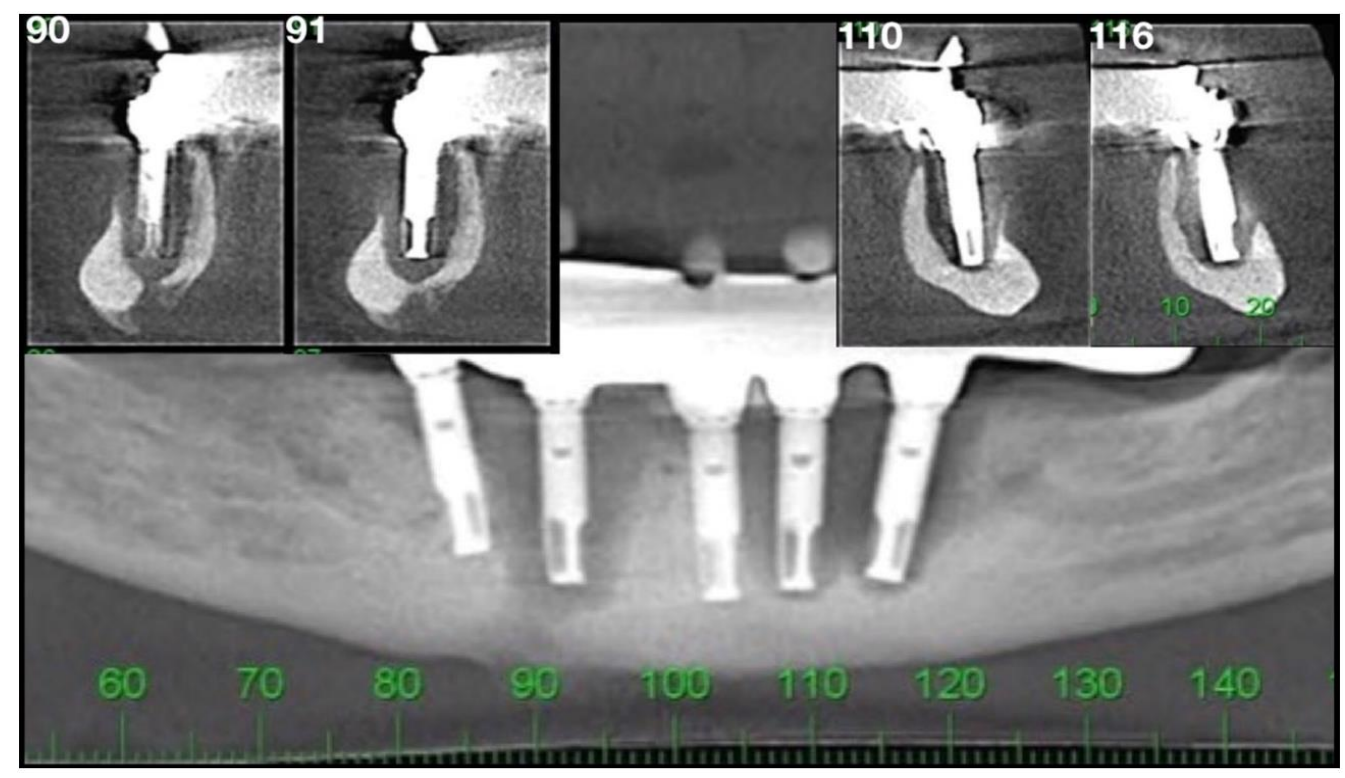

Fig. 8: Example of destructive peri-implant bone loss surrounding anodised implants (Nobel Biocare, Kloten, Switzerland) after 12 years of function. The axial slice at position 90 shows bone erosion through the inferior boarder of the mandible, with risk of pathologic fracture. Additionally, cavernous bone loss was observed in the 110 and 116 implant sites. Remedial treatment will be difficult, if not impossible. In addition, should new MRSIs be placed into this bone bed? 
The planktonic cloud released during osteotomy preparation is susceptible to both the host's immune system and antibiotics and many of these bacteria will succumb. Following the "pulse-type" surgical disturbance during implant placement, the bone bed rapidly returns to pre-disturbance ecological homeostasis (Shade et al., 2012) and bone and titanium osseointegrate. Since persister-cell biofilm formation is not initiated, late pathogenic biofilm reawakening does not occur and once integrated, smooth-surface implants provide decades of stable function with stable marginal bone height. Should the implant fail to integrate (overheating or overloading, for example) or lose integration at some future time, a thin, fibrous capsule forms and with a low bacterial load, bone loss is minimal, with little or no observable infection.

\section{Case Presentation}

The multiple variables that exist between individual patients and their health and habits, their treating practitioners, technicians, the use and abuse of their implant reconstructions, confound comparisons of their implant outcomes. However, in the case presentation below (Figs. 9 and 10), the only variable is implant surface - smooth in the maxilla and anodised in the mandible. This makes for an interesting comparison in outcomes. The implants (Nobel Biocare, Kloten,
Switzerland) were placed and restored by the same dentist, the prostheses were made by the same technician and the implants were exposed to the same oral and systemic patient environment.

A healthy 61-year-old male, non-smoking, nondiabetic patient presented with terminal bi-maxillary dentition. Initially, a maxillary clearance was performed, with the fitting of a full upper denture. After several months of post-extraction healing, 6 machined-surface implants were placed, which were installed using the traditional two stage protocol. Following six months of healing, they were uncovered and healing abutments were fitted. The implant in the ISO 15 location failed to integrate and was removed, along with a thin, periimplant connective tissue interface. With minimal bone loss, the site was be re-prepared and a wider $(5 \mathrm{~mm})$ implant was placed. A provisional bridge was fitted whilst the new implant integrated. Several months later, the case was completed with the placement of a 12-unit ceramo-metal bridge.

In 2002, a mandibular clearance was performed, with the fitting of a full lower denture. Four months later, 5 anodised implants were placed into the apparently healed mandible. Outcome at five years for the mandibular arch was excellent (Fig. 9).

However, radiographs taken at 11 years after placement, show unacceptable jawbone destruction associated with three of the mandibular implants (Fig. 10).

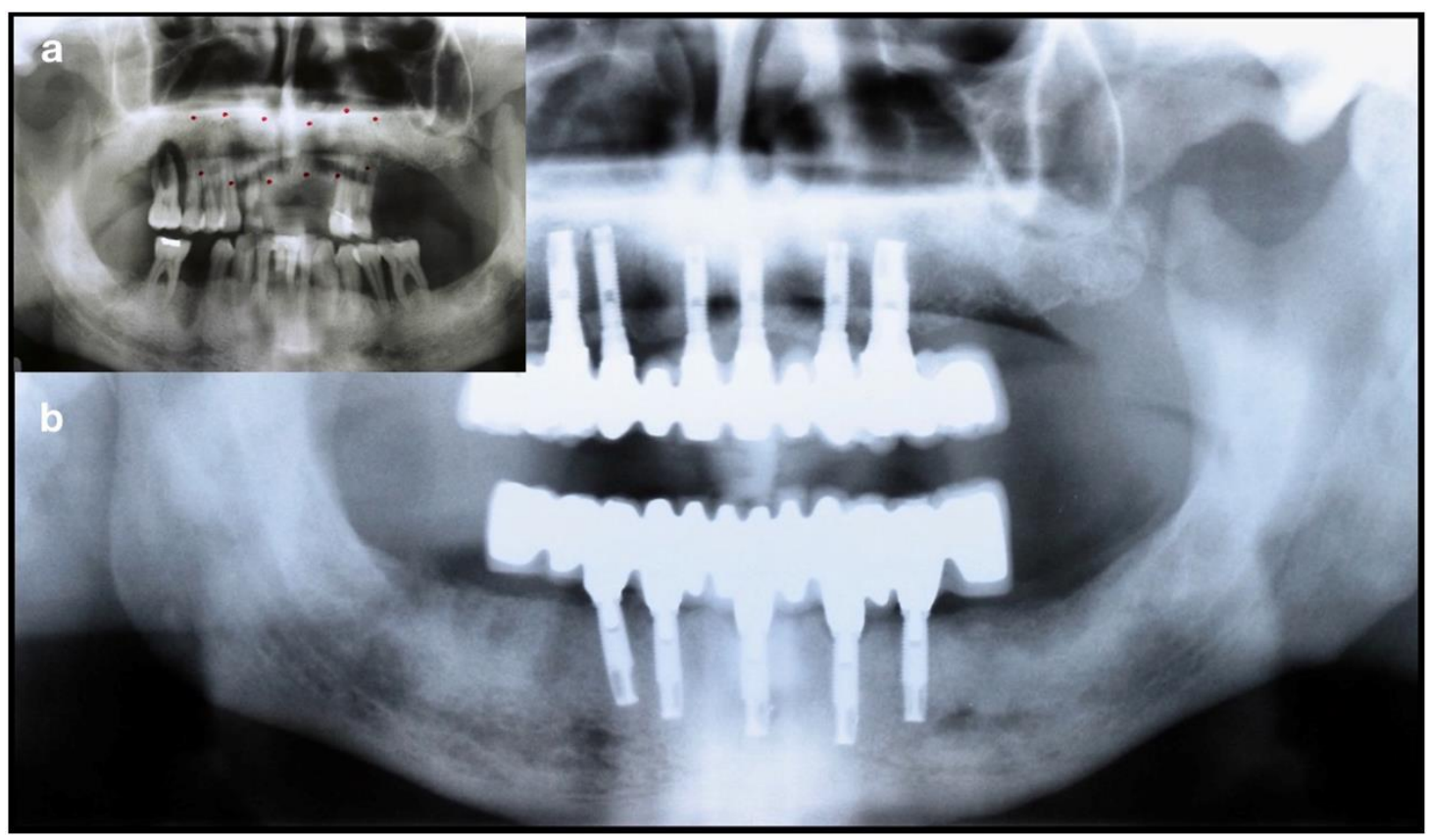

Fig. 9: (a) pre-operative OPG showing D5 bone (b) OPG taken after 5 years of mandibular implant function. There is no evidence of any peri-implant bone loss in either jaw. This finding is consistent with the slow onset of destructive, biofilm-mediated periimplant bone loss associated with MRSIs 


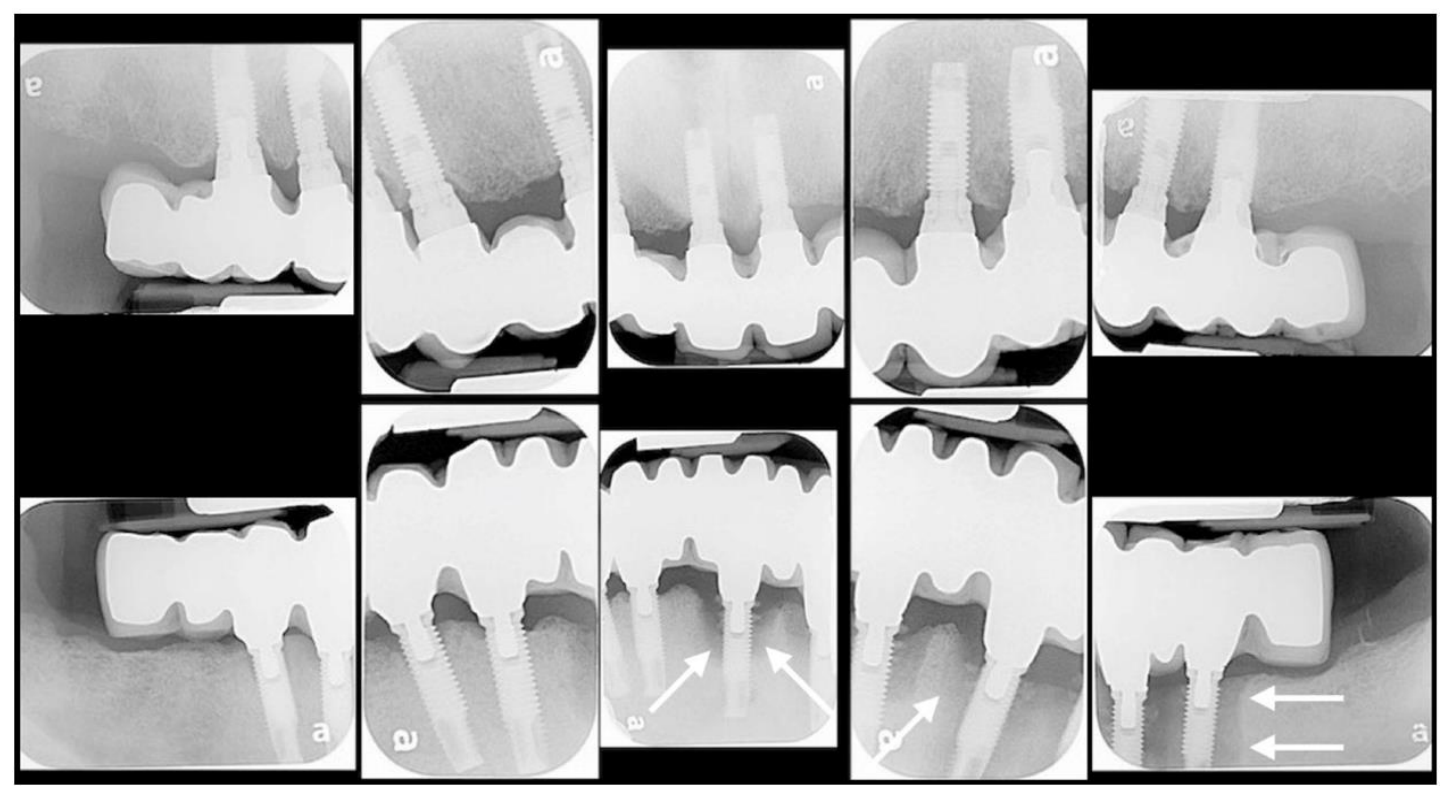

Fig. 10: The maxillary implants were placed in 1998, several months after the remaining teeth were removed. All were minimally rough (machined) surface implants. After 21 years of continuous function, there was no measurable bone loss around any of the implants. The mandibular implants were placed in 2002, 4 months after tooth removal (during which time an assumed spontaneous return to a sterile bone bed should have occurred). However, destructive, biofilm-mediated infection caused peri-implant osteomyelitis with complete bone loss surrounding the implants in the lower left quadrant. This level of tissue destruction violates Brånemark’s bioethic of “first, do no harm. Radiographs courtesy of Dr Greg Peake.

\section{Conclusion}

The understanding that the human jawbone supports permanent resident biofilm communities mandates an immediate re-appraisal of the use of implant surfaces known to be attractive to or known to foster planktonic bacterial adhesion and subsequent persister-cell biofilm formation. Importantly too, we need to understand that different surface topographies will be associated with different pathologies and that micropores and grooves foster endotoxin production. Additionally, since we can now classify bone quality using both radiographic anatomy and known microbial health or disease, only $\mathrm{H} 2$ and $\mathrm{H} 3$ bone should be considered suitable for implant placement. D1, D4 and D5 bone need to be returned to health prior to implant placement or avoided, with other treatment options offered. Replication studies confirming the presence of biofilms in human jawbone and relating those communities to bone quality and anatomical health are required.

\section{Acknowledgement}

Dr Stephen Nelson BSc, BDS, Dip Ed, PhD and Dr Graham Thomas BDS, PhD have spent the last decade investigating the existence or otherwise of a human jawbone microbiome. Over the past five years, I have been privileged to have been invited to be involved in their research. This paper reflects my perspective on their work and related research, in terms that are understandable to the non-microbiologist. It is a synopsis of our years of communication, discussions, analysis of data and personal interaction. These gentlemen are pioneers in exploring and discovering the bacterial communities in our jaws that we humans co-exist with. I owe a huge debt of gratitude to Stephen and Graham for including me in their journey, for enlightening me as to the existence of a human jaw microbiome, discovering how jawbone biofilm interacts with implanted surfaces and thus allowing a model to be generated for the aetiology of bacteriallymediated, surface-induced peri-implant bone destruction and for their assistance with the evolution of this manuscript. Their work is seminal and it should cause us to take stock and re-appraise the terms on which we practise modern-day implant dentistry.

\section{Conflicts of Interest}

The author declares there are no conflicts of interest.

\section{References}

Adell, R., U. Lekholm, B. Rockler and P.I. Brånemark, 1981. A 15-year study of osseointegrated implants in the treatment of the edentulous jaw. Int. J. Oral. Surg., 10: 387-416.

DOI: $10.1016 / \mathrm{S} 0300-9785(81) 80077-4$ 
Albrektsson, T., P.I. Brånemark, H. Hansson and J. Lindstrom, 1981. Osseointegrated titanium implants. Requirements for ensuring a long-lasting, direct bone-to-implant anchorage in Man. Acta Orthop. Scand, 52: 155-170.

Arnold, J. and G. Bailey, 2000. Surface finished on stainless steel reduces bacterial attachment and early biofilm formation. Poultry Sci., 79: 1839-1845. DOI: $10.1093 / \mathrm{ps} / 79.12 .1839$

Åstrand, P., B. Engquist, B. Anzén, T. Bergendal and M. Hallman et al., 2004. A three-year follow-up of a comparative study of ITI dental implants and brånemark system implants in the treatment of the partially edentulous maxilla. Clin. Impl. Dent. Rel. Res., 6: 130-141.

DOI: 10.1111/j.1708-8208.2004.tb00213.x

Åstrand, P., J. Ahlqvist, J. Gunne and H. Nilson, 2008. Implant treatment of patients with edentulous jaws: A 20-year follow-up. Clin. Impl. Dent. Rel. Res., 10: 207-217. DOI: 10.1111/j.1708-8208.2007.00081.x

Ballo, A., O. Omar, W. Xia and A. Palmquist, 2011. Dental implant surfaces-Physiochemical Properties, biological performance and trends. Intech. Open: Implant Dentistry-A Rapidly Evolv. Practice. DOI: $10.5772 / 17512$

Berglundh, T., 2019. Peri-implantitis and its prevention. Clin. Oral Impl. Res., 30: 150-155.

DOI: $10.1111 /$ clr. 13401

Berne, C., K. Ellison, A. Ducret and Y. Brun, 2018. Bacterial adhesion at the single-cell level. Nat. Rev. Microbiol., 16: 616-627.

DOI: $10.1038 / \mathrm{s} 41579-018-0057-5$

Bjarnsholt, T., 2013. The role of bacterial biofilms in chronic infections. APMIS Suppl., 136: 1-51. DOI: 10.1111/apm.12099

Brånemark, P.I. and B. Urbaschek, 1967. Endotoxins in tissue injury: Vital microscopic studies on the effect of endotoxin from $E$. coli on the microcirculation. Angiology, 18: 667-671. DOI: $10.1177 / 000331976701801103$

Brånemark, P.I. and U. Breine, 1964. Formation of bone marrow in isolated segment of rib periosteum in rabbit and dog. Ann. Hematol., 10: 236-252.

Brånemark, P.I., 1965. Capillary form and function the microcirculation of granulation tissue. Bibl. Anat., 7: 9-28.

Brånemark, P.I., G. Zarb and T. Albrektsson, 1985. Tissue-Integrated Prosthesis Osseointegration in Clinical Dentistry. 1st Edn., Quintessence, ISBN-10: 0-86715-129-3, pp: 350.

Browaeys, H., M. Dierens, C. Ruyffelaert, C. Matthijs and H. de Bruyn et al., 2014. Ongoing crestal bone loss around implants subjected to computer-guided flapless surgery and immediate loading using the allon-4 concept. Clin. Impl. Dent. Rel. Res., 17: 831-834. DOI: $10.1111 /$ cid.12197
Brynolf, I., 1967. A histological and Roentgenological Study of the Periapical Region of Human Upper Incisors. 1st Edn., Almqvist and Wiksell, pp: 176.

Carcuac, O., J. Derks, I. Abrahamson, J. Wennström and M. Petzold et al., 2017. Surgical treatment of periimplantitis. 3-year results from a randomized controlled clinical trial. J. Clin. Periodontol., 44: 1294-1303. DOI: 10.1111/jcpe.12813

Costerton, W., G. Geesey and K. Cheng, 1978. How bacteria stick. Sci. Am., 238: 86-95.

Costerton, W., R. Veeh, M. Shirtliff, M. Pasmore and C. Post et al., 2003. The application of biofilm science to the study and control of chronic bacterial infections. J. Clin. Invest., 112: 1466-1477. DOI: $10.1172 / \mathrm{JCI} 200320365$

Costerton, W., Z. Lewandowski, D. Caldwell, D. Korber and H. Lappin-Scott, 1995. Microbial biofilms. Ann. Rev. Microbiol., 49: 711-745. DOI: 10.1146/annurev.mi.49.100195.003431

Derks, J. and C. Tomasi, 2015. Peri-implant health and disease. A systematic review of current epidemiology. J. Clin. Periodontol., 42: 158-171. DOI: $10.1111 /$ jcpe. 12334

Deva, A., W. Adams and K. Vickery, 2013. The role of bacterial biofilms in device-associated infection. Plas. Recon. Surg., 132: 1319-1328. DOI: 10.1097/PRS.0b013e3182a3c105

Ehrlich, G., N. Hiller and F. Hu, 2008. What makes pathogens pathogenic. Genome Biol., 9: 255-255. DOI: $10.1186 / \mathrm{gb}-2008-9-6-225$

Ehrlich, G., R. Veeh, X. Wang, W. Costerton and J. Hayes et al., 2002. Mucosal biofilm formation on middle-ear mucosa in the chinchilla model of otitis media. JAMA, 287: 1710-1715. DOI: $10.1001 /$ jama.287.13.1710

Eliasson, S., C. Halvarsson and C. Ljungheimer, 1984. Periapical condensing osteitis and endodontic treatment. Oral Surg. Oral Med. Oral Pathol., 57: 195-199. DOI: 10.1016/0030-4220(84)90211-1

Fisher, R., B. Gollan and S. Helaine, 2017. Persistent bacterial infections and persister cells. Nat Rev. Microbiol., 15: 453-464. DOI: $10.1038 /$ nrmicro.2017.42

Gristina, A. and W. Costerton, 1985. Bacterial adherence to biomaterials and tissue. The significance of its role in clinical sepsis. J. Bone Joint Surg. Am., 67: 264-273.

Gristina, A., P. Naylor and Q. Myrvik, 1988-1989. Infections from biomaterials and implants: A race for the surface. Med. Prog. Technol., 14: 205-224.

Henry, P., A. Tan, B. Allan, J. Hall and C. Johansson, 2000. Removal torque comparison of TiUnite and turned implants in the greyhaound dog mandible. Applied Osseointegrat. Res., 1: 15-17. 
Jacombs, A., S. Tahir, H. Hu, A. Deva and A. Almatroudi et al., 2014. In vitro and in vivo investigation of the influence of implant surface on the formation of bacterial biofilms in mammary implants. Plast. Recon. Surg., 133: 1-8.

DOI: 10.1097/PRS.0000000000000020

Jemt, T., M. Olsson and V. Stenport, 2015. Incidence of first implant failure: a retrospective study of 27 years of implant operations at one specialist clinic. Clin. Impl. Dent. Rel. Res.

Jepsen, S., T. Berglundh, R. Genco, A. Aass and K. Demirel et al., 2015. Primary prevention of periimplantitis: Managing peri-implant mucositis. J. Clin. Periodontol., 42: 152-157.

DOI: $10.1111 /$ jcpe. 12369

Karl, M. and T. Albrektsson, 2017. Clinical performance of dental implants with a moderately rough (TiUnite) surface: A Meta-Analysis of Prospective Clinical Studies. Int. J. Oral Maxillofac. Impl., 32: 717-734. DOI: 10.11607/jomi.5699

Kassolis, J., M. Scheper and M. Reynolds, 2010. Histopathologic findings in bone from edentulous alveolar ridges: A role in osteonecrosis of the jaws. Bone, 47: 127-130. DOI: $10.1016 /$ j.bone.2010.04.588

Lewis, K., 2005. Persister cells and the riddle of biofilm survival. Biochemistry, 70: 267-274.

Lewis, K., 2010. Persister cells. Ann. Rev. Microbiol., 64: 357-372.

DOI: 10.1146/annurev.micro.112408.134306

Lidgren, L. and C. Törholm, 1980. Intramedullary reaming in chronic diaphyseal osteomyelitis. Clin. Ortho. Rel. Res., 151: 215-221.

Lindh, C., G. Oliveira, C. Leles, M. do Carmo Matias Freire and R. Ribeiro-Rotta, 2014. Bone quality assessment in routine dental implant treatment among Brazilian and Swedish specialists. Clin. Oral Impl. Res., 25: 1004-1009. DOI: 10.1111/clr.12221

Mader, J., M. Shirtliff and J. Calhoun, 1999. The host and skeletal infection: classification and pathogenesis of acute bacterial bone and joint sepsis. Bail Clin. Rheumat., 13: 1-20.

DOI: $10.1053 /$ berh. 1999.0003

Marsh, P., 2003. Are dental diseases examples of ecological catastrophes. Microbiology, 149: 279-294. DOI: 10.1099/mic.0.26082-0

Mukherjee, S. and B. Bassler 2019. Bacterial quorum sensing in complex and dynamic changing environments. Nat. Rev. Microbiol., 17: 371-382. DOI: $10.1038 / \mathrm{s} 41579-019-0186-5$

Nair, P., 2006. On the causes of persistent apical periodontitis: a review. Int. Endod. J., 39: 249-281. DOI: 10.1111/j.1365-2591.2006.01099.x
Nelson, C., A. McLaren, S. McLaren, J. Johnson and M. Smeltzer, 2005. Is aseptic loosening truly aseptic. Clin. Orthop. Relat. Res., 437: 25-30.

DOI: 10.1097/01.blo.0000175715.68624.3d

Nelson, S. and G. Thomas, 2010. Bacterial persistance in dentoalveolar bone following extraction: A microbiological study and implications for dental implant treatment. Clin. Impl. Dent. Rel. Res., 12: 306-314. DOI: 10.1111/j.1708-8208.2009.00165.x

Nelson, S., 2016. Improved osseointegration outcomes by surgical debridement of microbial biofilm in the dental implant bone bed. PhD Thesis, University of Sydney, Australia.

Parfitt, G., 1962. An investigation of the normal variations in alveolar bone trabeculation. Oral Surg. Oral Med. Oral Pathol., 15: 1453-1463. DOI: 10.1016/0030-4220(62)90409-7

Patzakis, M. and C. Zalavras, 2005. Chronic posttraumatic osteomyelitis and infected nonunion of the Tibia: Current management concepts. J. Am. Acad. Orthop. Surg., 13: 417-427.

Percival, S., L. Suleman, C. Vuotto and G. Donelli, 2015. Healthcare-associated infections, medical devices and biofilms: Risk, tolerance and control. J. Med. Microbiol., 64: 323-334. DOI: 10.1099/jmm.0.000032

Sanders, W. and C. Sanders, 1984. Modification of Normal Flora by Antibiotics: Effect on Individuals and Environment. In: New Dimensions in Antimicrobial Chemotherapy, Churchill Livingstone, New York, pp: 217-241.

Shade, A., H. Peter, S. Allison, M. Baho and M. Berga et al., 2012. Fundamentals of microbial community resistance and resilience. Microbiology, 3: 417-417. DOI: 10.3389/fmicb.2012.00417

Simion, M., M. Nevins, G. Rasperini and F. Tironi, 2018. A 13 to 32 Year retrospective study of bone stability for machined surface dental implants. Int. J. Perio Rest. Dent., 38: 489-493. DOI: 10.11607/prd.3694

Simpson, A., M. Deakin and J. Latham, 2001. Chronic osteomyelitis. The effect of the extent of surgical resection on infection-free survival. J. Bone Joint Surg. Br., 83: 403-407.

Siqueira, J.J., I. Rôças, D. Ricucci and M. Hülsmann, 2014. Causes and management of post-treatment apical periodontitis. Br. Dent. J., 216: 305-312. DOI: 10.1038/sj.bdj.2014.200

Smeets, R., B. Stadlinger, F. Schwarz, B. BeckBroichsitter and O. Jung et al., 2016. Impact of dental implant surface modifications on osseointegration. Biomed. Res. Int.

Sweet, M., A. Croquer and J. Bythell, 2011. Development of bacterial biofilms on artificial corals in comparison to surface-associated microbes of hard corals. Plos One, 6: e21195-e21195. DOI: 10.1371/journal.pone.0021195 
Tipton, C., M. Mathew, R. Wolcott, R. Wolcott and T. Kingston et al., 2017. Temporal dynamics of relative abundances and bacterial succession in chronic wound communities. Wound Repair Regen, 25: 673-679. DOI: 10.1111/wrr.12555

Trampuz, A., K. Piper, M. Jacobson, A. Hanssen and K. Unni et al., 2000. Sonication of removed hip and knee prostheses for diagnosis of infection. N Eng. J. Med., 357: 654-663.

DOI: $10.1056 /$ NEJMoa061588

Tunney, M., S. Patrick and M. Curran, 1998. Detection of prosthetic hip infection at revision arthroplasty by immunofluorescence microscopy and PCR amplification of the bacterial 16S rRNA gene. J. Clin. Microbiol., 37: 3281-3290.

Tuttle, M., E. Mostow, P. Mukherjee, F. Hu and R. Melton-Kreft et al., 2011. Characterization of bacterial communities in venous insufficiency wounds by use of conventional culture and molecular diagnostic methods. J. Clin. Micro., 49: 3812-3819. DOI: 10.1128/JCM.00847-11

Waldvogel, F., G. Medoff and M. Swartz, 1970. Osteomyelitis: A review of clinical features, therapeutic considerations and unusual aspects. $\mathrm{N}$ Eng. J. Med., 282: 198-206.

DOI: 10.1056/NEJM197001222820406
Wannfors, K. and B. Gazelius, 1991. Blood flow in jaw bones affected by chronic osteomyelitis. Br. J. OMFS, 29: 147-153.

Wannfors, K. and L. Hammarström, 1989. A proliferative inflammation in the mandible caused by implantation of an infected dental root. A possible experimental model for chronic osteomyelitis. Int. J. Oral Maxillofac. Surg., 18: 179-183.

Wennerberg, A. and T. Albrektsson, 2009. Effects of titanium surface topography on bone integration: A systematic review. Clin. Oral Impl. Res., 20: 172-184. DOI: 10.1111/j.1600-0501.2009.01775.x

Wennerberg, A., 1999. The role of surface roughness for implant incorporation in bone. Cells Mater., 9: $1-19$.

Zimmerli, W. and P. Sendi 2017. Orthopaedic biofilm infections. Acta Patho. Microbio., 125: 353-364. DOI: $10.1111 /$ apm. 12687

Zimmerli, W., 2014. Clinical presentation and treatment of orthopaedic implant-associated infection. J. Int. Med., 276: 111-119. DOI: 10.1111/joim.12233

Zimmerli, W., A. Trampuz and P. Oschner, 2004. Prosthetic-joint infections. N Eng. J. Med., 351: 1645-1654. DOI: 10.1056/NEJMra040181 